\title{
Approach to Imaging of Mediastinal Conditions in the Adult
}

\author{
Sanjeev Bhalla and Edith Marom
}

\section{Learning Objectives}

- To understand an approach to the adult mediastinum based on localization of lesions within the mediastinum and attenuation/intensity features on cross-sectional imaging.

- To highlight conditions that disregard the compartmental model.

- To use some cases to show the additional value of MR in evaluating the adult mediastinum.

\subsection{Introduction}

The mediastinum is an anatomic space defined by the thoracic inlet superiorly and the diaphragm inferiorly. It extends from the sternum to the vertebral bodies. Yet, despite its landmarks, there are no structures that completely separate the mediastinum from the neck above or the retroperitoneum below. Imaging of the mediastinum and generating a relevant different diagnosis rest on the principles of localization and characterization.

Once a process or mass can be localized to the mediastinum, it should be localized within the mediastinum. Many of us use an approach first championed by Ben Felson. Using a lateral radiograph or sagittal CT or MR, a line is drawn from the anterior tracheal wall to the posterior inferior vena cava. This line separates the anterior mediastinum from the middle mediastinum. A second line is drawn $1 \mathrm{~cm}$ posterior to the anterior margin of the vertebral body. This line separates the

\footnotetext{
S. Bhalla $(\bowtie)$

Mallinckrodt Institute of Radiology, Washington University,

Saint Louis, MO, USA

e-mail: sanjeevbhalla@wustl.edu

E. Marom

Radiology Department, The Chaim Sheba Medical Center,

Tel Aviv University, Ramat Gan, Israel
}

middle from the posterior mediastinum. No anatomic structures actually divide the mediastinal compartments, but this approach can be useful in creating concise, meaningful differential diagnoses. Keep in mind certain processes may involve more than one compartment and that a large mass may be hard to localize.

More recently, the International Thymic Malignancy Interest Group (ITMIG) has proposed a modification of lesion localization based on MDCT. In this model, three compartments are used: prevascular, visceral, and paravertebral. The main difference from the modified Felson technique is the inclusion of the heart and aorta in the visceral compartment (middle compartment) (Fig. 3.1).

After localization, cross-sectional imaging (either CT or MR) should be performed for lesion characterization. Knowing whether a lesion has a significant vascular, fluid or fat component can be very helpful in suggesting a more specific diagnosis. PET/CT is used mainly to evaluate lymph node metastases in lung cancer. It is used as well in the evaluation of solid mediastinal masses.

This approach of localization and characterization will provide the interpreting radiologist a solid foundation in imaging the mediastinum.

\subsection{Anterior Mediastinum/Prevascular Compartment}

Most anterior or prevascular mediastinal masses are thymic in origin. Even lymphomas and germ cell tumors tend to arise in cells within the thymus. A useful differential list should be based on age, as germ cell tumors are almost unheard of in patients older than 45 years. Most anterior mediastinal masses tend to be lymphomas, germ cell tumors, or thymomas. Many texts will include thyroid goiter in the list for anterior mediastinal lesions. We, however, have found that most goiters tend to extend into the middle mediastinum or visceral compartment (Fig. 3.2). 

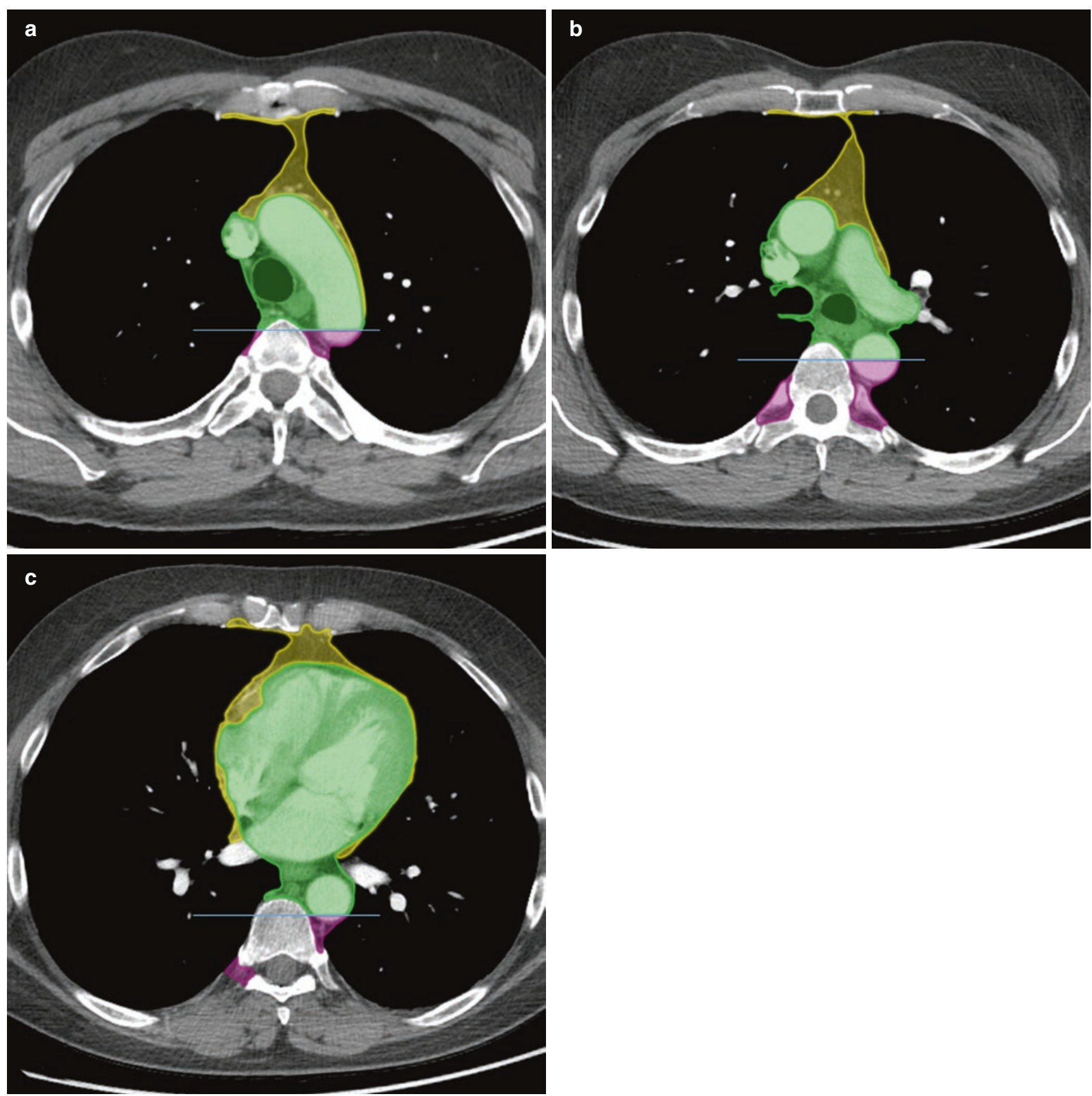

Fig. 3.1 ITMIG definition of the mediastinal compartments at the level of the transverse aorta (a), left pulmonary artery (b), and heart (c). The prevascular compartment is anterior or peripheral to the pericardium (X

Observing fluid attenuation or intensity can be very helpful in approaching anterior mediastinal masses. Pure cystic lesions are benign (usually thymic or pericardial cysts). Separating pericardial from thymic cysts is based on location as thymic cysts tend to be spade-shaped and reside in the thymic bed, while pericardial cysts tend to be rounder and are more commonly found in the right cardiophrenic angle (Fig. 3.3). As the amount of soft tissue within the lesion increases, one should consider the increased likelihood of a

color), whereas the paravertebral compartment is separated from the visceral compartment by a line ( $\mathrm{X}$ color) $1 \mathrm{~cm}$ posterior to the anterior vertebral body border

malignancy. Both lymphoma and cystic thymoma will tend to have soft tissue elements that will enhance on MR or CT (Fig. 3.4). Germ cell tumors also follow this rule. The classic teaching is that the germ cell tumor should be fat in attenuation. Many teratomas do contain some fat elements, but almost all are cystic (Fig. 3.5). As with the other lesions, if the soft tissue elements dominate, then a malignant germ cell tumor should be favored, such as seminoma. Interestingly, malignant germ cell tumors are quite rare in female patients. 

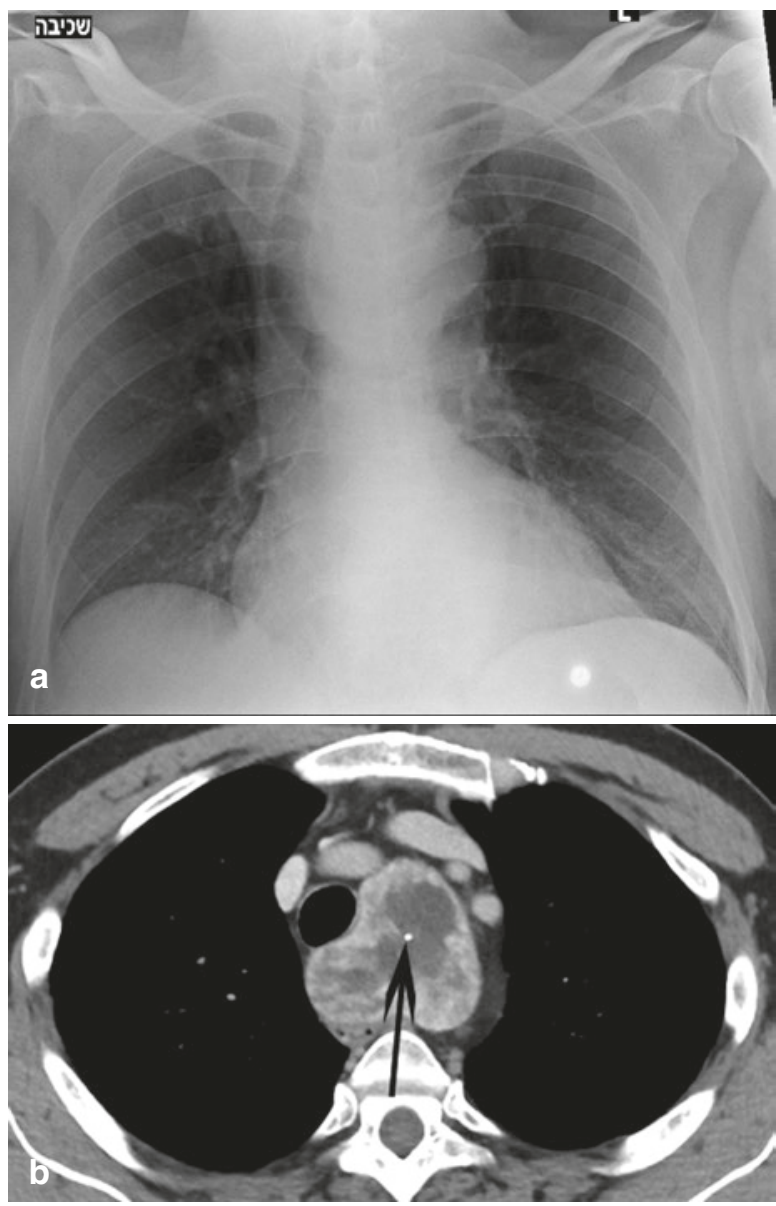

Fig. 3.2 Thyroid goiter. Frontal chest radiograph (a) of an asymptomatic 74-year-old man demonstrates a mass in the mediastinum displacing the trachea to the left. Axial (b) and coronal reformations (c) of a contrast-enhanced CT confirm the mass is in the visceral or middle mediastinum, shows intense enhancement, similar to the enhancement

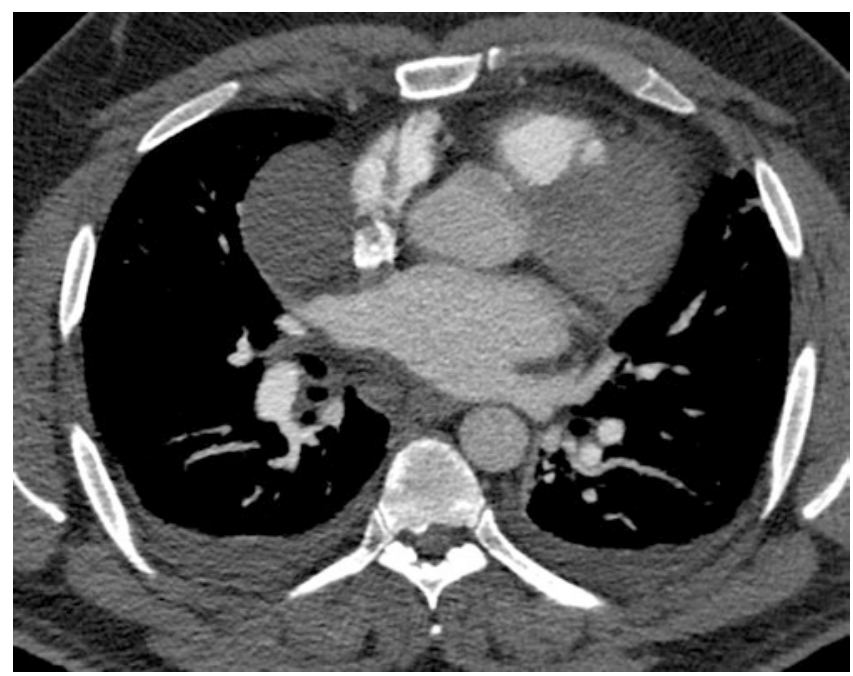

Fig. 3.3 Pericardial cyst. Axial contrast-enhanced CT (a) of a 56-yearold man demonstrates a cystic mass abutting the right heart border with imperceptible walls, of water density and no enhancing nodule or septa, typical for a pericardial cyst

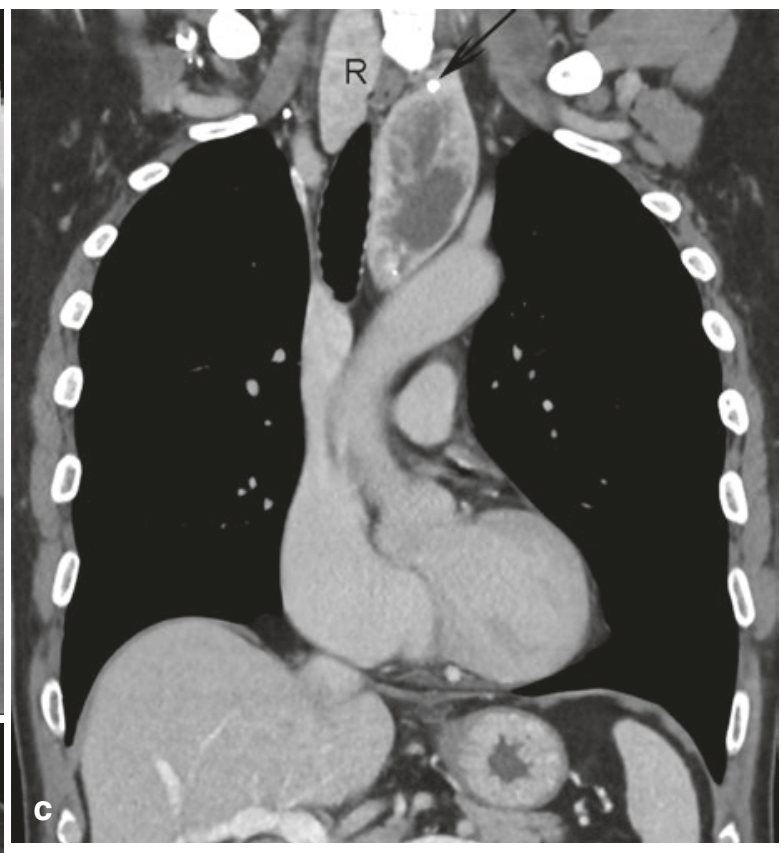

of the right thyroid lobe ( $\mathrm{R}$ in image $\mathrm{C}$ ), and contains course calcifications (arrows) and low attenuation regions with it. These findings, of a heterogeneous intensely enhancing mass, with low attenuation regions, and course calcifications, connecting to the thyroid, are typical for intrathoracic extension of a goiter

The visualization of fat intensity or attenuation can also be very helpful. In the anterior or prevascular mediastinum, most fatty masses are benign. As described above, an anterior mediastinal mass with fat and fluid suggests a teratoma (benign germ cell tumor) (Fig. 3.5). If the mass is purely fat, it may be the very rare thymolipoma but more likely will be a fat pad or anterior hernia (Morgagni hernia). Coronal or sagittal images are quite helpful in depicting vessels originating below the diaphragm. Visualization of these are key in separating hernias from fat pads or fatty tumors. In our practices, infarction of a pericardial fat pad or fat within the Morgagni hernia may present with chest pain. In the era of the frequent use of CT in the evaluation of chest pain, these areas of fat necrosis can simulate a neoplasm. Awareness of this potential pitfall will allow the patients to be treated appropriately.

Calcification can also be helpful. The incidence of calcification in thymomas varies from 10 to $40 \%$ (Fig. 3.6). Circular 

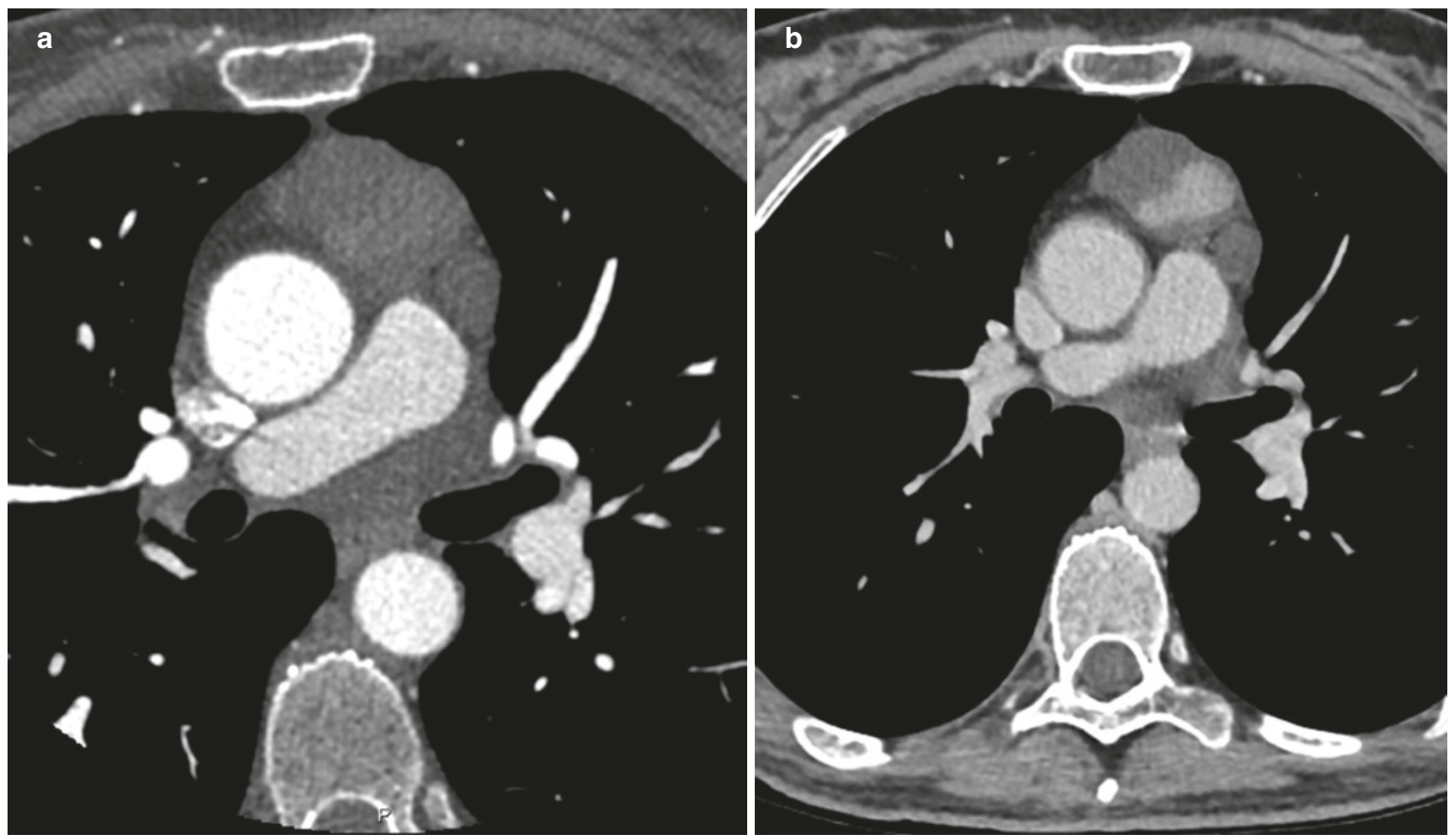

Fig. 3.4 Cystic thymoma. Axial view from a contrast-enhanced coronary artery $\mathrm{CT}$ in a 51-year-old woman demonstrated a cystic mass in the prevascular mediastinum. At this phase of early imaging after contrast injection, intralesional nodular enhancement is not readily seen, better demonstrated on a routine contrast-enhanced chest CT (B).

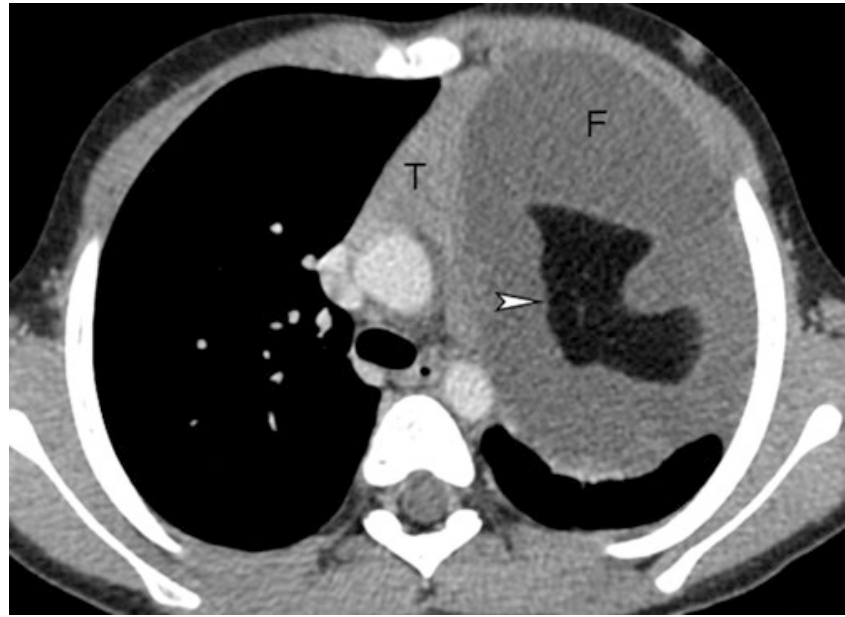

Fig. 3.5 Mature teratoma. Axial view of a contrast-enhanced chest CT at the level of the thymus (T) in a 5-year-old boy. There is a fluid-filled (F) large prevascular mass containing obvious fat

peripheral calcification may occur in solid thymomas. Teratomas contain calcium in about $35 \%$ of cases. Untreated lymphomas do not calcify and about $5 \%$ of them show calcifications after radiation therapy. Peripheral circular calcification can be a finding of an aneurysm. In this location, many
Delayed imaging after contrast enhancement or MR imaging with its improved contrast resolution is used to ensure cystic lesions in the prevascular mediastinum do not contain enhancing soft tissue which usually indicated malignancy, as was proven in this cystic type B1 thymoma

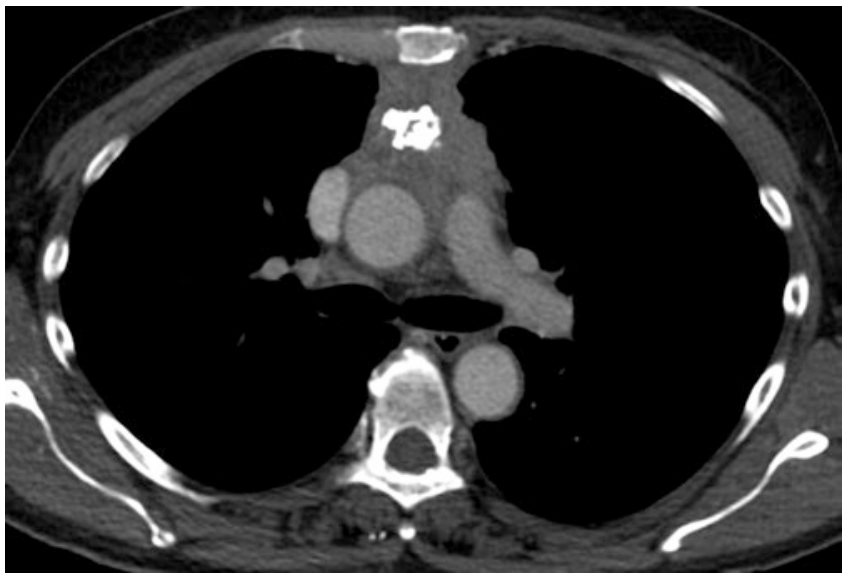

Fig. 3.6 Thymoma with calcifications. Contrast-enhanced chest CT of a 65-year-old woman shows a prevascular mass with dense calcifications proven at resection to represent a type B3 thymoma. Thymoma may present with dense or even curvilinear calcifications

such aneurysms represent bypass graft aneurysms. The presence of mediastinal wires should be a clue to this potential diagnosis.

Vascular or hyperenhancing lesions may present within the anterior or prevascular mediastinum. Often, these 
are related to the heart, ascending aorta. Rarely, ectopic parathyroid adenomas may present as vigorously enhancing anterior prevascular masses.

\section{Key Point}

- Most anterior mediastinal masses are of thymic origin. Patient age and attenuation characteristics are key in narrowing the differential diagnosis. MR can be helpful in characterizing cystic lesions and in diagnosing thymic hyperplasia.

\subsection{Middle Mediastinum/Visceral Compartment}

Most middle mediastinal or visceral compartment masses represent lymphadenopathy, foregut duplication cysts, vascular lesion, or esophageal processes. They usually present with right paratracheal widening on a frontal chest radiograph or occasionally the doughnut sign on a lateral examination. As with the anterior mediastinal conditions, assessment of attenuation or intensity can be helpful. In the ITMIG model, the heart is included in this compartment. In our experience, left ventricular and left atrial conditions may occasionally simulate middle mediastinal, visceral masses.

If the mass is fluid in characteristic, the middle mediastinal mass most likely represents a foregut duplication cyst (either bronchogenic or esophageal). These cysts occasionally are higher in attenuation as a result of infection (Fig. 3.7) or hemorrhage and may even contain a fluid-calcium level from milk of calcium. The risk of malignancy in these conditions tends to almost nonexistent. As with anterior mediastinal lesions, the ratio of soft tissue to fluid needs to be considered. A foregut duplication cyst should have no soft tissue, enhancing element. If soft tissue is encountered, one must consider a potentially more significant process, usually low-attenuating lymphadenopathy. Such low-attenuating lymph nodes may be encountered in lung cancer, mucinous
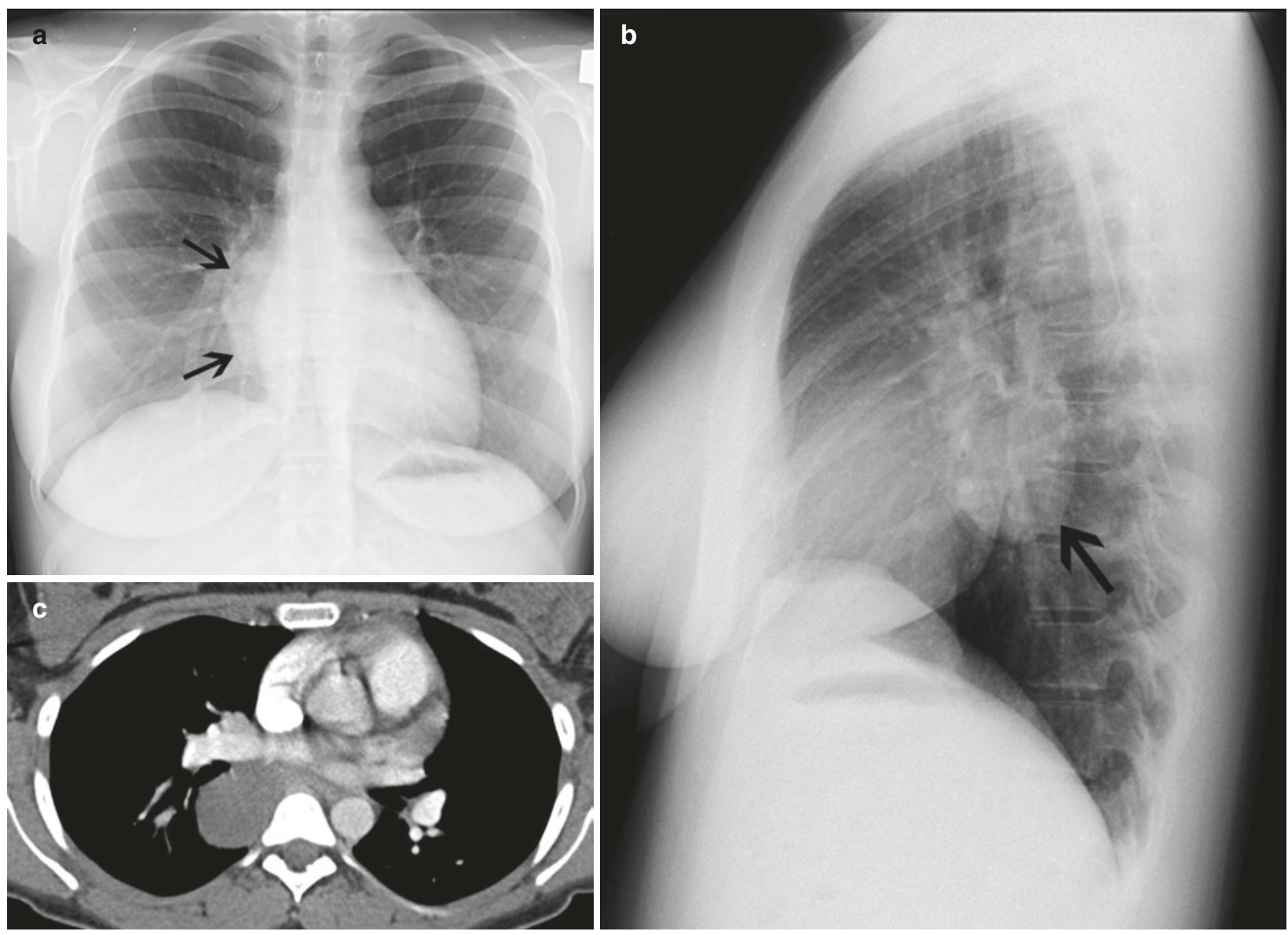

a homogeneous mass abutting the takeoff of the right lower lobe bron-

Fig. 3.7 Asymptomatic bronchogenic cyst in a 19-year-old woman incidentally discovered on a preoperative chest radiograph $(\mathbf{a}, \mathbf{b})$. There is a mass posterior to the heart (arrows in A) displacing the right lower lobe bronchovascular structures laterally but best appreciated on the lateral film (arrow in B). Contrast-enhanced chest CT (b) demonstrates chus and esophagus measuring $41 \mathrm{HU}$, often encountered in duplication cysts which contain proteinaceous material. Note the absence of any thickened or enhancing septa or nodules 


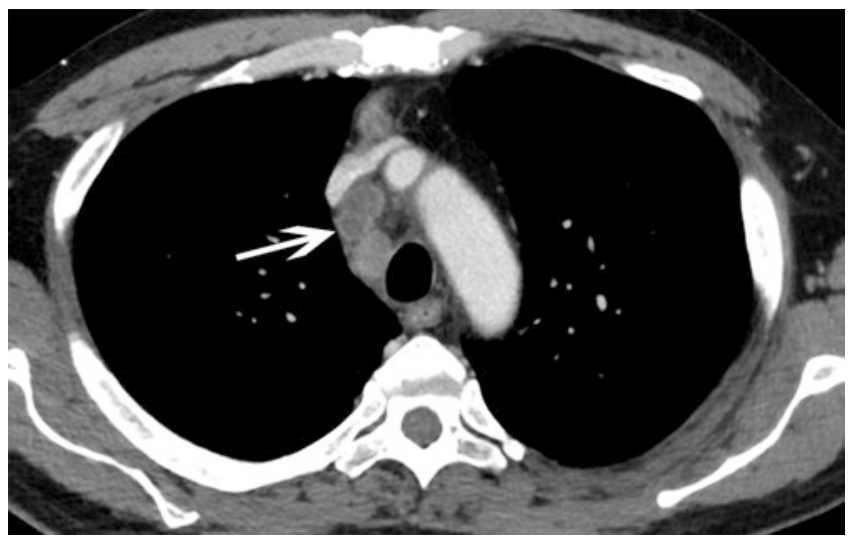

Fig. 3.8 Tuberculosis. Contrast-enhanced chest CT of a 64-year-old febrile new immigrant. Chest radiograph at presentation (a) demonstrates loss of the right paratracheal line which was clearly present on a baseline chest radiograph (arrow in b) performed 1 year earlier Contrast-enhanced chest CT (c) confirms that indeed there are enlarged right paratracheal lymph nodes, some of which have peripheral enhancement and a low attenuation center (arrow). Such low attenuation lymph nodes in the correct clinical setting are highly suggestive of tuberculosis

neoplasms, and mycobacterial disease (Fig. 3.8). In the superior mediastinum, papillary thyroid carcinoma can rarely mimic a foregut duplication cyst.

Unlike the anterior mediastinum or visceral compartment, fat cannot be considered benign. Although esophageal or tracheal lipomas and esophageal fibrovascular polyps contain fat, so may mediastinal liposarcomas. Although rare, these lesions may insinuate through the mediastinum and often have a predilection for the middle mediastinum.

Hypervascular lesions in the middle mediastinum or visceral compartment are most often hypervascular lymph nodes, or an intrathoracic extension of a goiter. Rarely a paraganglioma may present in this space. Interestingly, many of these lesions tend to abut the left atrium. The hypervascular lymph nodes (defined as higher in attenuation than skeletal muscle) may be seen with melanoma, plasmacytoma, Castleman's disease, Kaposi sarcoma, and thyroid and renal cell cancer (Fig. 3.9). When the high attenuating structure is tubular, a vessel must be considered. Aortic arch anomalies and azygous vein enlargement often present as a middle mediastinal mass on radiography. Azygous vein variants tend to enlarge on portable radiographs (when the patient is supine) compared with upright radiographs.

Most mediastinal lymphadenopathy will present in the middle mediastinum or visceral compartment. Occasionally, these nodes will be calcified. Most often these calcified nodes are indicative of an old granulomatous process such as healed tuberculosis or histoplasmosis or sarcoidosis, but care must be taken to remember that certain tumors also tend to present with calcified mediastinal lymph nodes, including ovarian serous adenocarcinomas, mucinous colon neoplasms, and osteosarcomas.

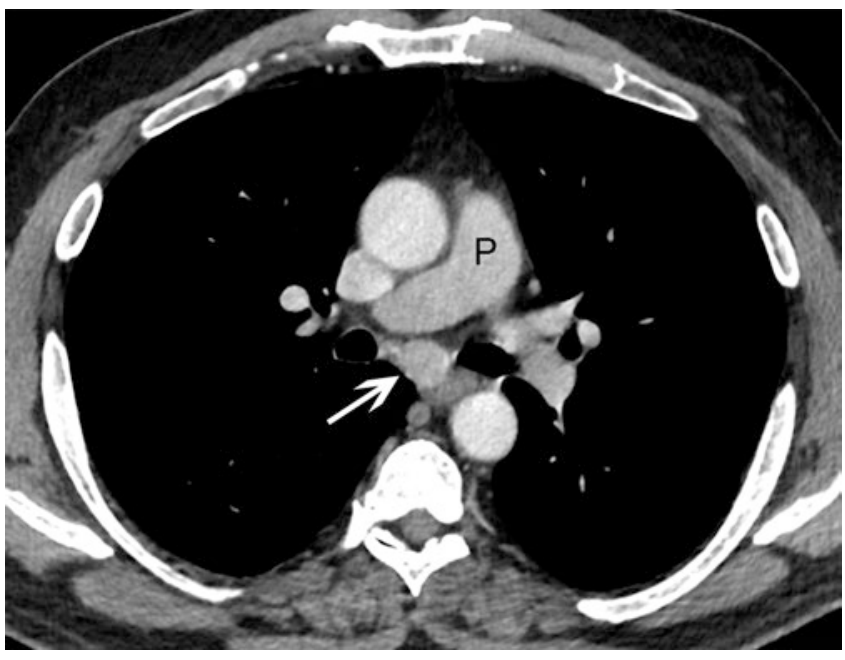

Fig. 3.9 Renal cell enhancing metastasis to the subcarinal lymph node in a 65-year-old man with renal cell carcinoma. Axial contrast-enhanced chest CT demonstrates subcarinal lymphadenopathy (arrow) at the level of the pulmonary artery $(\mathrm{P})$. The subcarinal lymph node shows avid enhancement, measured as $105 \mathrm{HU}$, identical to the contrast within the pulmonary artery

Another potential for a perceived middle mediastinal mass on radiography will be a dilated esophagus. Although a distal mass may also result in esophageal dilatation, it is usually only achalasia that results in esophageal widening that can be seen on a chest radiograph.

\section{Key Point}

- Most middle mediastinal masses will consist of lymphadenopathy, duplication cysts, vascular lesions, or esophageal masses. Attenuation characteristics of the lymphadenopathy compared to skeletal muscle can be helpful at honing in on the correct diagnosis.

\subsection{Posterior Mediastinum/Paravertebral Compartment}

A vast majority of posterior mediastinal or paravertebral masses will be neurogenic in origin (Fig. 3.10). In adults, these tend to be benign nerve sheath tumors, usually schwannomas and neurofibromas. In kids and younger adults, these tend to be sympathetic ganglion in origin, such as ganglioneuroblastoma, neuroblastoma, or ganglioneuroma. The key in separating the two groups is to assess the overall shape, comparing $\mathrm{Z}$-axis to the XY-axis. The nerve sheath tumors tend to be spherical (equal in all three axes), while the ganglion lesions are longer in the $\mathrm{Z}$-axis and are more cylindrical (akin to a sausage). Osseous lesions represent the second most common group of posterior mediastinal disease. 

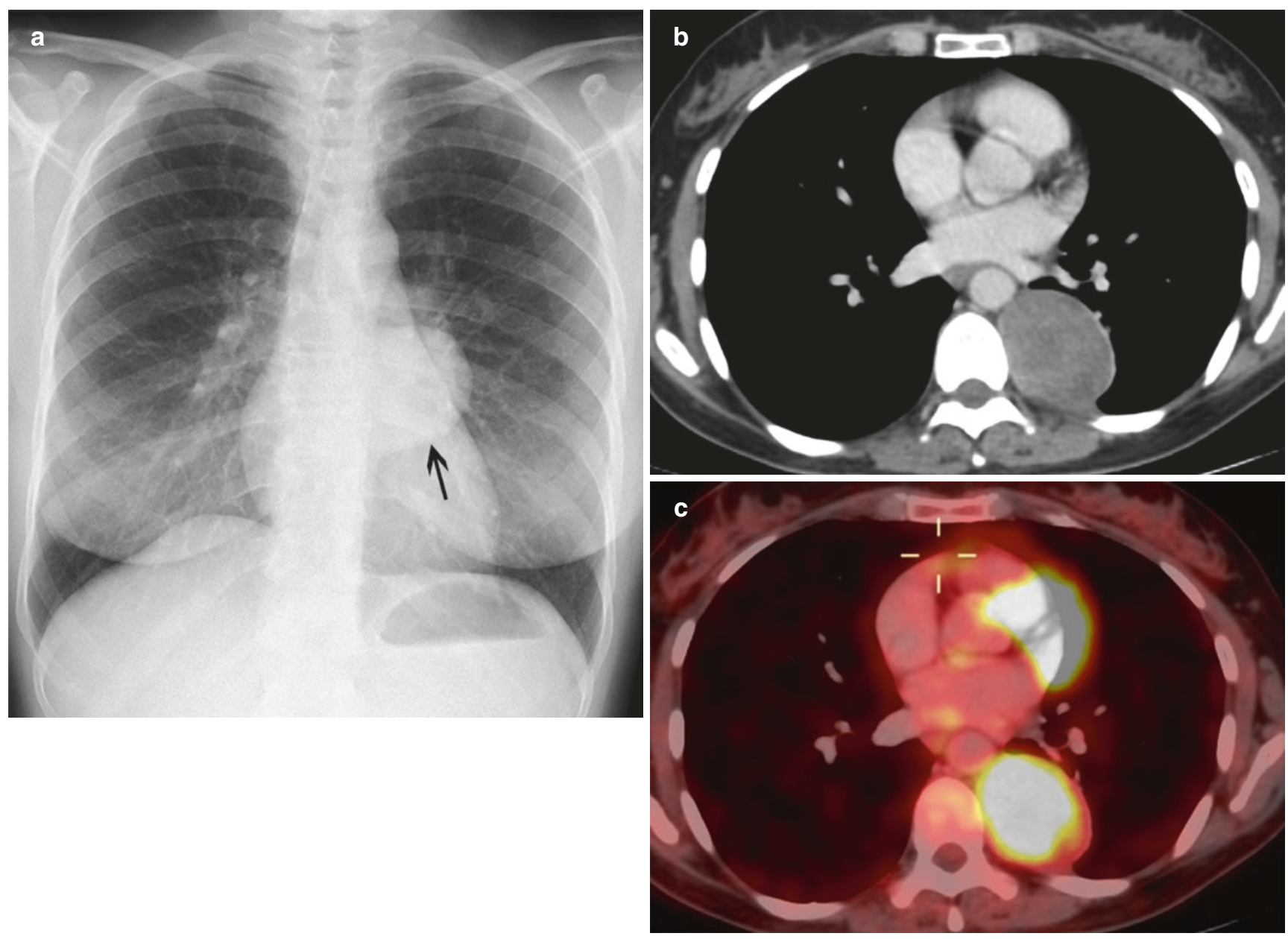

Fig. 3.10 Benign peripheral nerve sheath tumor. Frontal chest radiograph in an asymptomatic 51-year-old woman demonstrates a posterior mediastinal mass (arrow). Contrast-enhanced chest CT (b) at the level of the heart demonstrates the mass is centered in the paravertebral

Although metastases are often considered, one cannot forget about diskitis/osteomyelitis. This latter condition can present with insidious back pain and can easily be overlooked.

As with the other compartments, attenuation or intensity can be helpful. On CT, a potential pitfall is that myelin-rich neurogenic lesions may look cystic. For this reason, we often rely on MR with posterior mediastinal/paravertebral lesions. True posterior mediastinal cystic lesions are rare. Although neuroenteric cysts exist, they are often associated with vertebral anomalies and rarely encountered de novo in adults. Instead, a cystic lesion in the posterior mediastinum is much more likely to represent a lateral meningocoele or post-traumatic nerve root avulsion.

Fatty lesions are unusual in the posterior mediastinum but when encountered may invoke extramedullary hematopoiesis. Although rare, in patients with anemia, extramedullary hematopoiesis may develop in this space. The etiology of this condition remains unknown. Some authors have postulated that it develops from extruded marrow, while others have suggested that it develops from totipotent cells in the paravertebral space. When the patient is anemic, extramedullary hematopoiesis mediastinum. FDG PET/CT (c) revealed the mass was FDG avid with an SUVmax of 6.8. Most masses in this location represent benign peripheral nerve sheath tumors. Their FDG avidity is variable and may be very high despite being benign

will present with bilateral masses that enhance similar to the spleen without a connecting bridge. As the patient returns to normal hematocrit, the yellow marrow will take over. The net effect is bilateral posterior mediastinal fatty masses. In the elderly, Bochladek hernias should be included in the differential diagnosis. Often the diaphragmatic defect can be seen.

Hypervascular lesions in in the posterior mediastinum or paravertebral space are less helpful than with the other compartments. Most often these are related to an aneurysmal aorta or enlarged collateral vessels as with aortic coarctation. As described above, extramedullary hematopoiesis may be seen with bilateral hypervascular paravertebral masses.

\section{Key Point}

- Most posterior mediastinal masses are neurogenic in origin. Osseous lesions, however, should not be forgotten. Mutiplanar reconstructions and MR are particularly helpful in this compartment. 


\subsection{Conditions that Disregard the Compartment Model}

Certain conditions tend to disregard the compartment model of the mediastinum. Even with these lesions understanding the attenuation or intensity can be helpful. These include infection and hematoma, which will result in fat stranding and soft tissue attenuation throughout the mediastinum, often in more than one compartment.

Lymphangiomas and hemangiomas also tend to disregard the compartment model. The former tend to be fluid in their attenuation and insinuate throughout, while the latter will be higher in attenuation.

Of course, lung cancer may present with metastases to any compartment and unfortunately and tends to metastasize to more than one region.

\section{Key Point}

- Infections, lymphangiomas, and hematomas tend to disregard the compartmental model.

\subsection{Conclusion}

The mediastinum represents a space that may be impacted by a large number of lesions. Regardless whether one uses the modified Felson technique or the newer ITMIG approach, having an approach based on location and characterization will allow the radiologist the ability to create a useful, targeted differential diagnosis (Table 3.1).

\section{Take-Home Messages}

- A solid approach to the adult mediastinum uses the patient's age, lesion cross-sectional attenuation/ intensity, and lesion location to generate the differential diagnosis.

- This compartment model is based on certain anatomic landmarks (Fig. 3.1).

- Although most lesions will be characterized by CT, MR may have additional value in characterizing cystic lesions, diagnosing thymic hyperplasia and separating neurogenic from osseous lesions in the posterior mediastinum/paravertebral compartment.

Table 3.1 Location and characteristic approach to mediastinal masses in the adult

\begin{tabular}{|c|c|c|c|c|}
\hline Mediastinal compartment & Most common & Fluid & Fat & Hypervascular \\
\hline Anterior/prevascular & $\begin{array}{l}\text { Thymoma } \\
\text { Lymphoma } \\
\text { Germ cell tumor }\end{array}$ & $\begin{array}{l}\text { Thymic cyst } \\
\text { Pericardial cyst } \\
\text { Lymphoma }\end{array}$ & $\begin{array}{l}\text { Teratoma } \\
\text { Thymolipoma } \\
\text { Fat pad } \\
\text { Morgagni hernia }\end{array}$ & $\begin{array}{l}\text { Heart* } \\
\text { Coronary arteries* } \\
\text { Ascending aorta* } \\
\text { Parathyroid adenoma }\end{array}$ \\
\hline Middle/visceral & $\begin{array}{l}\text { Lymphadenopathy } \\
\text { Duplication cyst } \\
\text { Vascular anomaly }\end{array}$ & $\begin{array}{l}\text { Duplication cyst } \\
\text { Lymphadenopathy }\end{array}$ & $\begin{array}{l}\text { Lipoma } \\
\text { Liposarcoma } \\
\text { Fibrovascular polyp } \\
\text { Hiatal hernia }\end{array}$ & $\begin{array}{l}\text { Arch anomaly } \\
\text { Azygous vein } \\
\text { Lymph nodes } \\
\text { Goiter } \\
\text { Heart* }\end{array}$ \\
\hline Posterior/paravertebral & $\begin{array}{l}\text { Neurogenic } \\
\text { Osseous met } \\
\text { Diskitis }\end{array}$ & $\begin{array}{l}\text { Neurenteric cyst } \\
\text { Lateral meningocoele } \\
\text { Traumatic }\end{array}$ & $\begin{array}{l}\text { Extramedullary hematopoiesis } \\
\text { Bochladek hernia }\end{array}$ & Aorta or collaterals \\
\hline More than one & $\begin{array}{l}\text { Infection } \\
\text { Hematoma } \\
\text { Lung cancer }\end{array}$ & Lymphangioma & $\begin{array}{l}\text { Liposarcoma } \\
\text { Lipomatosis }\end{array}$ & Hemangioma \\
\hline
\end{tabular}

The main difference between the older Felson technique and the newer ITMIG approach is inclusion of the heart in anterior mediastinum vs. visceral compartment. The conditions marked with an asterisk (*) may vary on localization based on technique used 


\section{Suggested Readings}

Adam A, Hochholzer L. Ganglioneuroblastoma of the posterior mediastinum: a clinicopathologic review of 80 cases. Cancer. 1981;47:373-81.

Baron RL, Sagel SS, Baglan RJ. Thymic cysts following radiation therapy for Hodgkin disease. Radiology. 1981;141:593-7.

Carter BW, Benveniste MF, Madam R, et al. ITMIG classification of mediastinal compartments and multidisciplinary approach to mediastinal masses. RadioGraphics. 2017;37:413-36.

Chen JL, Weisbrod GL, Herman SJ. Computed tomography and pathologic correlations of thymic lesions. J Thorac Imaging. 1988;3:61-5.

Cohen AJ, Thompson LN, Edwards FH, et al. Primary cysts and tumours of the mediastinum. Ann Thorac Surg. 1991;51:378-86.

Do YS, Im JG, Lee BH, et al. CT findings in malignant tumors of thymic epithelium. J Comput Assist Tomogr. 1995;19:192-7.

Erasmus JJ, McAdams HP, Donnelly LF, Spritzer CE. MR imaging of mediastinal masses. Magn Reson Imaging Clin North Am. 2000;8:59-89.

Faul JL, Berry GJ, Colby TV, et al. Thoracic lymphangiomas, lymphangiectasis, lymphangiomatosis, and lymphatic dysplasia syndrome. Am J Respir Crit Care Med. 2000;161:1037-46.

Gaerte SC, Meyer CA, Winer-Muram HT, et al. Fat-containing lesions of the chest. RadioGraphics. 2002;22:615-78.

Hoffman OA, Gillespie DJ, Aughenbaugh GL, Brown LR. Primary mediastinal neoplasms (other than thymoma). Mayo Clin Proc. 1993;68:880-91.

Jeung M-Y, Gasser B, Gangi A, et al. Imaging of cystic masses of the mediastinum. RadioGraphics. 2002;22:S79-93.

Jolles H, Henry DA, Roberson JP, et al. Mediastinitis following median sternotomy: CT findings. Radiology. 1996;201:463-6.

Knapp RH, Hurt RD, Payne WS, et al. Malignant germ cell tumors of the mediastinum. J Thorac Cardiovasc Surg. 1985;89:82-9.

Long JA Jr, Doppman JL, Nienhuis AW. Computed tomographic studies of thoracic extramedullary hematopoiesis. J Comput Assist Tomogr. 1980;4:67-70.

Moeller KH, Rosado-de-Christenson ML, Templeton PA. Mediastinal mature teratoma: imaging features. Am J Roentgenol. 1997;169:985-90.

McAdams HP, Rosado-de-Christenson M, Fishback NF, Templeton PA. Castleman disease of the thorax: radiologic features with clinical and histopathologic correlation. Radiology. 1998;209:221-8.

Miles J, Pennybacker J, Sheldon P. Intrathoracic meningocele. Its development and association with neurofibromatosis. J Neurol Neurosurg Psychiatry. 1969;32:99-110.

Miyake H, Shiga M, Takaki H, et al. Mediastinal lymphangiomas in adults: CT findings. J Thorac Imaging. 1996;11:83-5.

Moran CA, Suster S. Primary germ cell tumors of the mediastinum: I. Analysis of 322 cases with special emphasis on teratomatous lesions and a proposal for histopathologic classification and clinical staging. Cancer. 1997;80:681-90.
Nakata H, Nakayama C, Kimoto T, et al. Computed tomography of mediastinal bronchogenic cysts. J Comput Assist Tomogr. 1982;6:733-8.

Pombo F, Rodriguez E, Mato J, et al. Patterns of contrast enhancement of tuberculous lymph nodes demonstrated by computed tomography. Clin Radiol. 1992;46:13-7.

Riccardo Marano MD, Carlo Liguori MD, Giancarlo Savino MD, et al. Cardiac silhouette findings and mediastinal lines and stripes radiograph and CT scan correlation. Chest. 2011;139:1186-96.

Rosado-de-Christenson ML, Galobardes J, Moran CA. Thymoma: radiologic-pathologic correlation. RadioGraphics. 1992;12:151-68.

Rosado-de-Christenson ML, Pugatch RD, Moran CA, Galobardes J. Thymolipoma: analysis of 27 cases. Radiology. 1994;193:121-6.

Rosado-de-Christenson ML, Templeton PA, Moran CA. From the archives of the AFIP. Mediastinal germ cell tumors: radiologic and pathologic correlation. RadioGraphics. 1992;12:1013-30.

Rossi SE, McAdams HP, Rosado-de-Christenson ML, et al. Fibrosing mediastinitis. RadioGraphics. 2001;21:737-57.

Shaffer K, Rosado-de-Christenson ML, Patz EF Jr, et al. Thoracic lymphangioma in adults: CT and MR imaging features. Am J Roentgenol. 1994;162:283-9.

Spizarny DL, Rebner M, Gross BH. CT evaluation of enhancing mediastinal masses. J Comput Assist Tomogr. 1987;11:990-3.

Strollo DC, Rosado-de-Christenson ML. Tumors of the thymus. J Thorac Imaging. 1999;14:152-71.

Strollo DC, Rosado de Christenson ML, Jett JR. Primary mediastinal tumors. Part 1: tumours of the anterior mediastinum. Chest. 1997; 112:511-22.

Strollo DC, Rosado-de-Christenson ML, Jett JR. Primary mediastinal tumors: part II. Tumours of the middle and posterior mediastinum. Chest. 1997; 112:1344-57.

Suwatanapongched T, Gierada DS. CT of thoracic lymph nodes. Part II: diseases and pitfalls. Br J Radiol. 2006;79:999-1006.

Takahashi K, Al-Janabi NJ. Computed tomography and magnetic resonance imaging of mediastinal tumors. J Magn Reson Imaging. 2010;32:1325-39.

Thacker PG, Mahani MG, Heider A, Lee EY. Imaging evaluation of mediastinal masses in children and adults practical diagnostic approach based on a new classification system. Thorac Imaging. 2015;30:247-67.

Whitten CR, Khan S, Munneke GJ, Grubnic S. A diagnostic approach to mediastinal abnormalities. RadioGraphics. 2007;27:657-71.

Woodring JH, Loh FK, Kryscio RJ. Mediastinal hemorrhage: an evaluation of radiographic manifestations. Radiology. 1984;151:15-21.

Zylak CJ, Eyler WR, Spizarny DL, Stone CH. Developmental lung anomalies in the adult: radiologic-pathologic correlation. RadioGraphics. 2002;22:S25-43.

Zylak CJ, Pallie W, Jackson R. Correlative anatomy and computed tomography: a module on the mediastinum. RadioGraphics. 1982;2(4):555-92.

Open Access This chapter is licensed under the terms of the Creative Commons Attribution 4.0 International License (http://creativecommons. org/licenses/by/4.0/), which permits use, sharing, adaptation, distribution and reproduction in any medium or format, as long as you give appropriate credit to the original author(s) and the source, provide a link to the Creative Commons license and indicate if changes were made.

The images or other third party material in this chapter are included in the chapter's Creative Commons license, unless indicated otherwise in a credit line to the material. If material is not included in the chapter's Creative Commons license and your intended use is not permitted by statutory regulation or exceeds the permitted use, you will need to obtain permission directly from the copyright holder. 